\title{
Utilization of a Personal Computer for the Microstructural Analysis of a Duplex Stainless Steel
}

\author{
Seiji KUNIMITSU, Osamu SUZUKI, Shin-ichiro OZEKI, Yasutoshi SASAKI, Yukio ADACHI and Yuzo HOSOI
}

Department of Materials Science and Engineering, Nagoya University, Furo-cho, Chikusa-ku, Nagoya, Aichi-ken, 464 Japan.

(Received on January 23, 1990; accepted in the final form on March 9, 1990)

\begin{abstract}
The combination of a personal computer and EPMA has been utilized in order to develop a simplified microanalysis equipment system which has nearly the same analyzing power in specifications as CMA or MA in image analysis.

Image analyzed data for a duplex stainless steel 329J1 from the present system was compared with that from CMA and found to be in fairly good agreement with color mapping of the concentrations of $\mathrm{Cr}$ and $\mathrm{Ni}$.

The phase identification for $\alpha$ and $\gamma$ phases by $\mathrm{Cr} / \mathrm{Ni}$ partition ratio was also accomplished.

KEY WORDS: image analysis; personal computer; EPMA; duplex stainless steel; phase identification; color mapping.
\end{abstract}

\section{Introduction}

Computer Aided Microanalyzer (CMA) and MacroAnalyzer (MA) were recently developed for the qualitative and quantitative evaluation of metallic microstructures. ${ }^{1,2)}$ These analyzers are consist of a skillful combination of EPMA (electron prove microanalyzer) with image processing, and are effective tools for microstructure analysis because of very rapid response times and excellent sensitivity in a relatively wide area of microstructures.

In the present work, a trial was made utilizing the combination of a personal computer with EPMA for microanalysis which has nearly the same analyzing power as CMA in specifications in order to develop a more conventional and lower cost analyzing equipment system. Some applications and limitations of usage are also discussed.

\section{Experimental Procedure}

The EPMA(JCXA-733) and the personal computer (PG, NEG-PC9801VM2) were connected by RS232G cables as shown in Fig. 1. The characteristic X-ray signal for a specific element existing on the surface of a specimen is input into the $\mathrm{PC}$ directly from the EPMA which was drived in surface scanning mode under the following operating conditions: accelerating voltage $15 \mathrm{kV}$, emission current $6 \mathrm{nA}$, beam diameter $2 \mu \mathrm{m}$, counting time per a point $2 \mathrm{~s}$. A duplex stainless steel 329J1 composed of $\alpha$ and $\gamma$ phases in Table 1 was used for the image analysis of microstructure. The specific elements to be measured were $\mathrm{Cr}$ and $\mathrm{Ni}$, and the $\mathrm{X}$-ray signals of these elements were directly input into the $\mathrm{PG}$ and then converted to concentrations after ZAF calibration ${ }^{3)}$ in the $\mathrm{PG}$.

Multi-faced outputs are available using these data. Concentration distribution of $329 \mathrm{~J} 1 \mathrm{was}$ color-mapped in 16 levels in different colors. The area fraction for

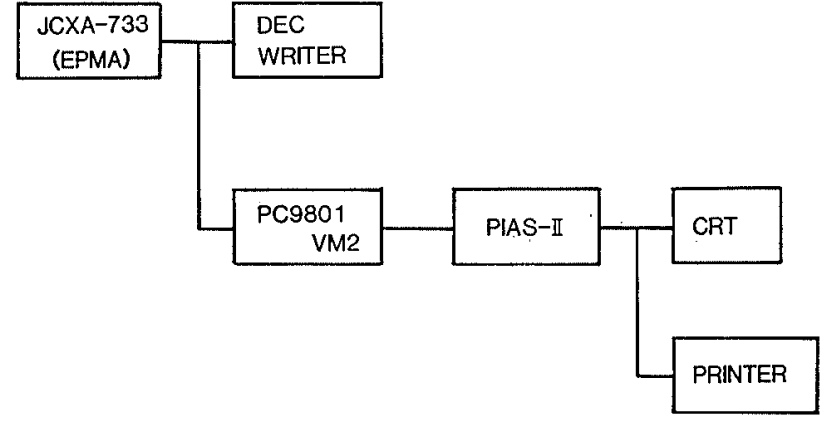

Fig. 1. Schematic illustration of a newly developed image analyzer composed of a personal computer and EPMA.

Table 1. Chemical composition of specimens used.

\begin{tabular}{lcccccccc}
\hline & $\mathrm{Mn}$ & $\mathrm{Cu}$ & $\mathrm{Ni}$ & $\mathrm{Cr}$ & $\mathrm{V}$ & $\mathrm{Mo}$ & $\mathrm{C}$ & $\mathrm{P}$ \\
\hline $329 \mathrm{J1}$ & - & - & 4.25 & 24.72 & - & 1.83 & 0.016 & 0.032 \\
$16 \mathrm{Cr}$ & 2.88 & 0.11 & 9.9 & 16.1 & 0.032 & 0.12 & - & - \\
$18.5 \mathrm{Cr}$ & 3.38 & 0.14 & 9.4 & 18.5 & 0.064 & 0.12 & - & - \\
$20.5 \mathrm{Cr}$ & 4.62 & 0.24 & 10.1 & 20.5 & 0.12 & 0.23 & - & - \\
\hline
\end{tabular}

each concentration level was also calculated. The identification of $\alpha$ and $\gamma$ phases through the partition ratio of $\mathrm{Cr} / \mathrm{Ni}$ and the estimation of area fraction in both phases was also conducted. Some austenitic stainless steels, listed in Table 1 , were also used in order to compare the analytical value of $\mathrm{Cr}$ obtained by this system with that of chemical analysis.

\section{Results and Discussion}

The microstructure of 329J1 solution-treated for $3.6 \mathrm{ks}$ at $1573 \mathrm{~K}$, followed by $\gamma$ transformation at $1273 \mathrm{~K}$ for $21.6 \mathrm{ks}$ and etched by Villera reagent is shown in Fig. 2. Spheroidal or rodlike precipitates are $\gamma$ phases and the matrix is $\alpha$ phase.

Fig. 3 shows the relation between concentrations of 


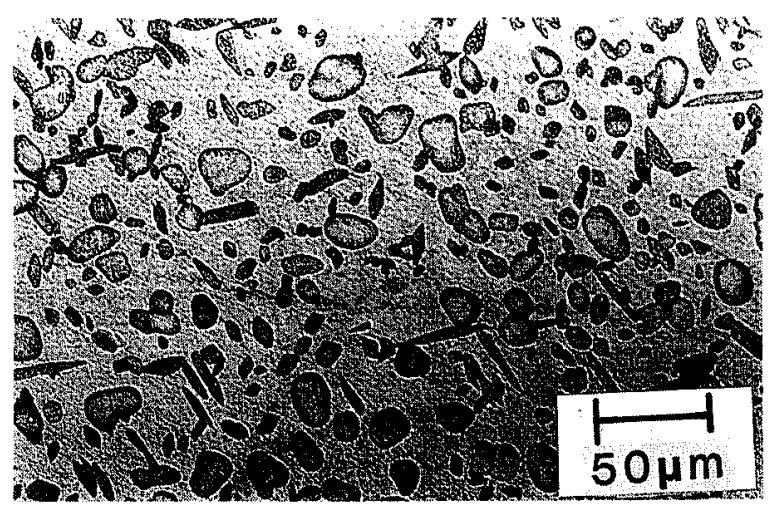

Fig. 2. Microstructure of $329 \mathrm{~J} 1$ stainless steel solutiontreated at $1573 \mathrm{~K}$ followed by $\gamma$ formation at $1273 \mathrm{~K}$ for $21.6 \mathrm{ks}$.

Table 2. Example of analysis data input to PC9801 from EPMA.

\begin{tabular}{cccr}
\hline$X$ & $Y$ & $X R(2)$ & $X R(3)$ \\
\hline 16124 & 31782 & 3330 & 1147 \\
16126 & 31782 & 3407 & 1131 \\
16128 & 31782 & 3418 & 1212 \\
16130 & 31782 & 3166 & 645 \\
16132 & 31782 & 3313 & 563 \\
16134 & 31782 & 3284 & 563 \\
16136 & 31782 & 3222 & 574 \\
16138 & 31782 & 3281 & 545 \\
16140 & 31782 & 3239 & 557 \\
16142 & 31782 & 3241 & 582 \\
16144 & 31782 & 3181 & 563 \\
16146 & 31782 & 3271 & 580 \\
\hline
\end{tabular}

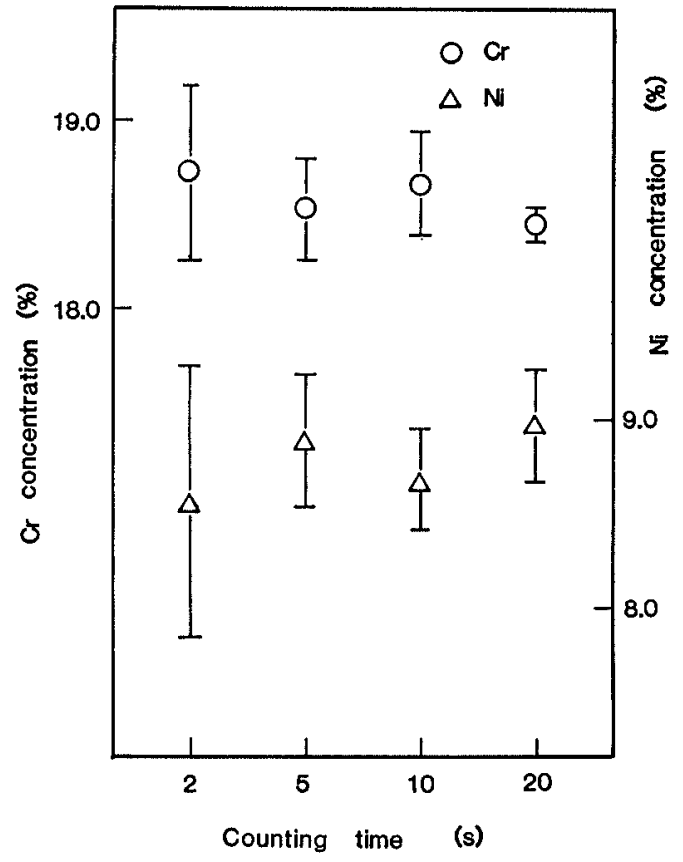

$\mathrm{Ni}$ and $\mathrm{Gr}$ and $\mathrm{X}$-ray counting time. The longer the counting time, the smaller the scatter of concentrations. From the viewpoint of prompt image processing, $2 \mathrm{~s}$ counting was adopted, since in the range from 2 to $20 \mathrm{~s}$ counting, the mean values were within the range of allowances.

X-ray intensity data input from the EPMA to the $P G$ is shown in Table 2. Columns, $X$ and $Y$, show positions analyzed on the $X$ and $Y$ axes. $X R(2)$ and $X R(3)$ are the $X$-ray intensity of $\mathrm{Cr}$ and $\mathrm{Ni}$, respectively. The values in the $X$ and $Y$ columns show that the electron beam whose diameter is fixed at $2 \mu \mathrm{m}$ was driven laterally along the $X$ axis and the characteristic $X$-ray signals generated for each $2 \mu \mathrm{m}$ square and integrated for $2 \mathrm{~s}$ are listed. These data were converted to concentrations by ZAF (Atomic number correction, Absorption correction and Fluorescence correction) calibration. ${ }^{3)}$

The flow chart of image analysis in the present system is shown in Fig. 4 . Figs. 5 and 6 show the color mapping of the concentrations of $\mathrm{Cr}$ and $\mathrm{Ni}$ in the microstructure of $329 \mathrm{~J} 1$, respectively, for $2 \mathrm{~s}$ counting. In figures composed of $51 \times 51$ fine picture
Fig. 3.

Relation between $\mathrm{Ni}$ and $\mathrm{Cr}$ concentration and counting time of $\mathrm{X}$-ray signal in $329 \mathrm{~J} 1$ stainless steel.
Indication of color map
by concentration

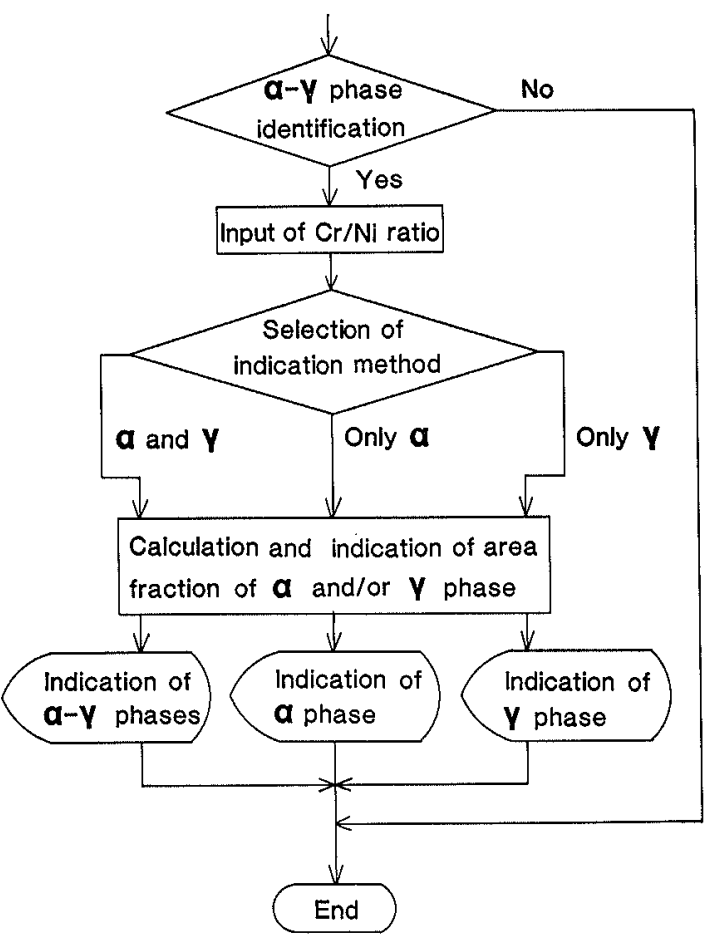

Fig. 4. Flow chart in image analyzing of the present system. 

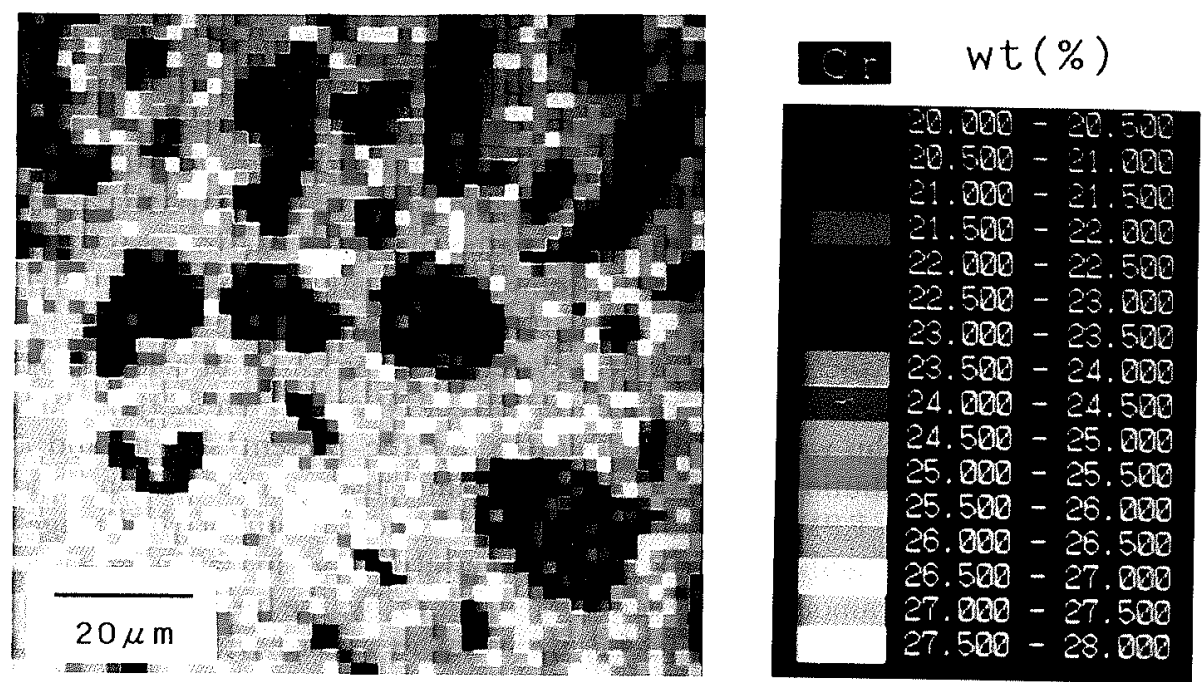

A.F. (\%)

Fig. 5. Color mapping of Cr concentration in 329J1 stainless steel by the present system. (A.F.: Area fraction)
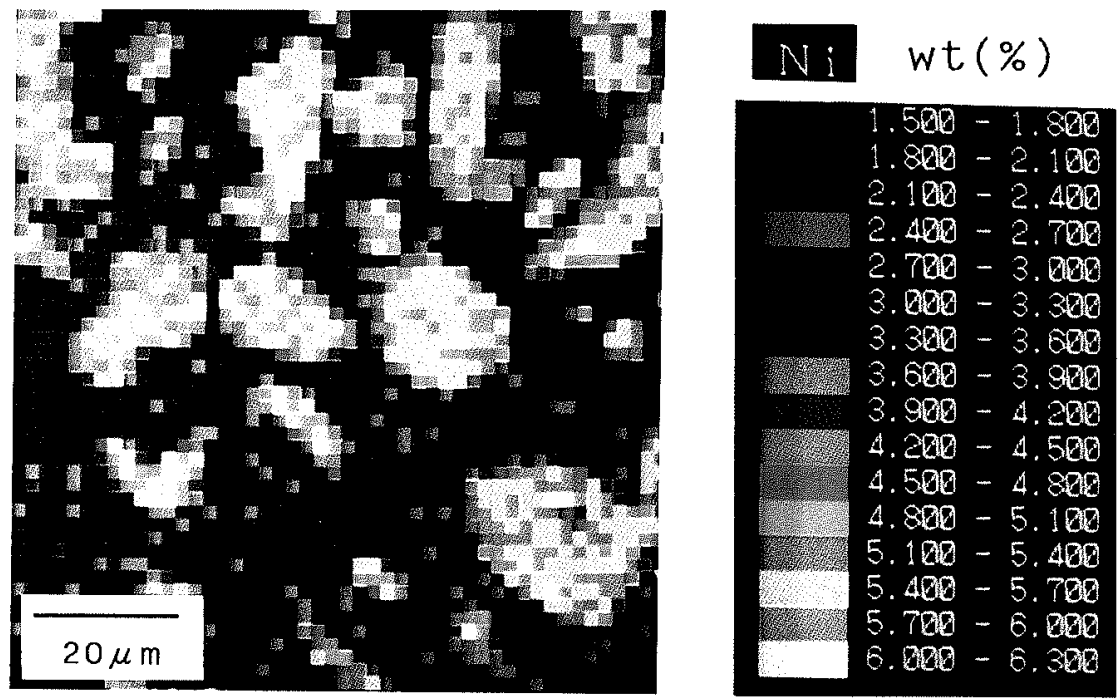

A.F. (\%)

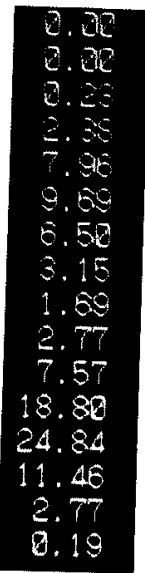

0.19

Fig. 6. Color mapping of Ni concentration in $329 \mathrm{~J} 1$ stainless steel by the present system. (A.F.: Area fraction)

elements (pixels) $2 \mu \mathrm{m} \times 2 \mu \mathrm{m}$ in size, the same as the output of the GMA, visual color presentation of concentration level with 16 colors can be accomplished. Each concentration level, whose range can be set arbitrarily, is colored and measured in area fractions so that estimation of the segregation of atoms is possible. It was found, in comparison with the microstructure in Fig. 2, that $\mathrm{Cr}$ segregates in $\alpha$ phase, $\mathrm{Ni}$ in $\gamma$ phase and that each element is not uniformly distributed in each phase. Table 3 shows the concentrations of $\mathrm{Gr}$ and $\mathrm{Ni}$ in 10 randomly selected point areas and the respective partition ratio of $\mathrm{Cr}$ / $\mathrm{Ni}$. The value of $\mathrm{Gr} / \mathrm{Ni}$ is a measure for identifying both phases since it closely corresponds to the phases which are determined by conventional etching techniques.

In this computer identification of phases, the binarizing threshold is thought to be between 4.052 and 6.476 , since the values are between 6.476 and 6.642 in $\alpha$ phase and between 3.920 and 4.052 in $\gamma$ phase,

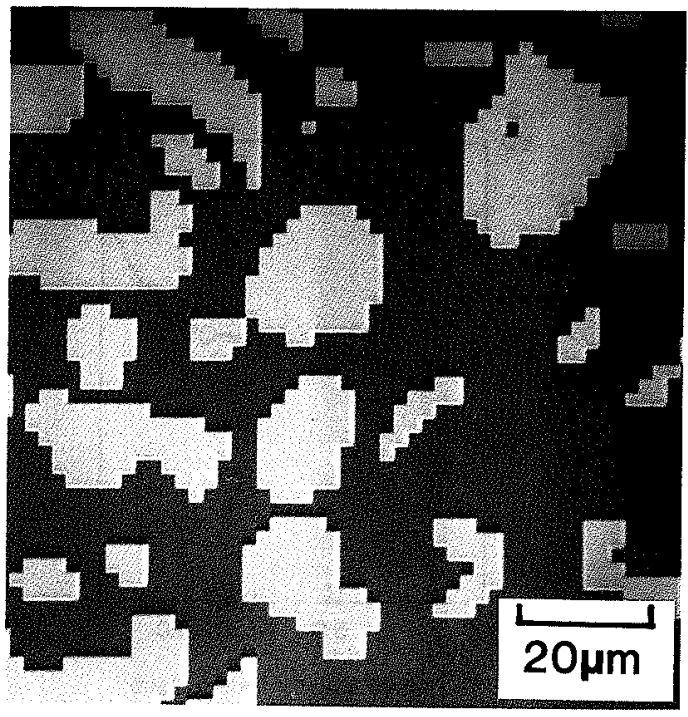

Fig. 8. Phase identification by partition ratio $(\mathrm{Cr} / \mathrm{Ni}) 5.5$ in $329 \mathrm{~J} 1$ stainless steel.

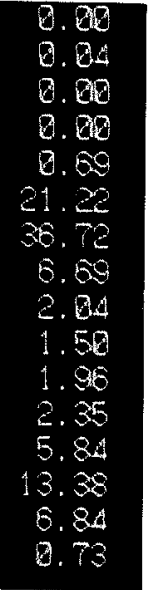


clearly identified by the etching. Fig. 7 shows the relation between the threshold value and $\gamma$ phase area fraction. The optimum threshold value is considered to be 5.5 where the tangential of the curve is minimum and the $\gamma$ phase area fraction yields $34 \%$. Fig. 8 is composed of $51 \times 51$ picture elements, each element being $2 \mu \mathrm{m}$ square in size, and shows the $\gamma$ phase presentation obtained at a threshold value of 5.5. Taking into consideration of the magnification in Figs. 2 and 8 , this computer-identified picture yields fairly good agreement with the microstructure in Fig. 2. In identifying microstructures by this way, various advanced image analyses, size distributions, mean free paths, etc., are available. The EPMA operating conditions and binarizing threshold, in data treated thus, are of very importance, since the amount of characteristic X-ray signal which is highly dependant upon it is the sole information for estimation of the concentration on the spot. In this sense, enhancing the X-ray flux is effective. However, from the standpoint of rapid image processing, which is a primary concept in image analysis, this demand is incompatible. Accordingly the optimum conditions for image analysis are placed on a balance between these two demands. Fig. 9 shows the reliability in the estimation of chemical composition by the present system when compared with traditional chemical analysis. Determination of the concentration of $\mathrm{Ni}$

Table 3. $\mathrm{Cr}$ and $\mathrm{Ni}$ concentration and partition ratio in $\alpha$ and $\gamma$ phases in $329 \mathrm{~J} 1$ stainless steel.

\begin{tabular}{cccccc}
\hline \multicolumn{2}{c}{ Position } & \multirow{2}{C}{$\begin{array}{c}\mathrm{Cr} \\
(\mathrm{wt} \%)\end{array}$} & $\begin{array}{c}\mathrm{Ni} \\
(\mathrm{wt} \%)\end{array}$ & $\mathrm{Cr} / \mathrm{Ni}$ & Phase \\
\cline { 1 - 2 } 16164 & 31836 & 24.131 & 3.726 & 6.476 & $\alpha$ \\
16188 & 31836 & 22.328 & 5.655 & 3.948 & $\gamma$ \\
16138 & 31838 & 24.182 & 3.654 & 6.618 & $\alpha$ \\
16128 & 31844 & 24.215 & 3.688 & 6.566 & $\alpha$ \\
16156 & 31848 & 22.557 & 5.567 & 4.052 & $\gamma$ \\
16214 & 31848 & 22.304 & 5.649 & 3.948 & $\gamma$ \\
16172 & 31850 & 24.548 & 3.696 & 6.642 & $\alpha$ \\
16200 & 31858 & 24.292 & 3.682 & 6.598 & $\alpha$ \\
16166 & 31864 & 22.452 & 5.728 & 3.920 & $\gamma$ \\
16212 & 31872 & 22.412 & 5.642 & 3.972 & $\gamma$ \\
\hline
\end{tabular}

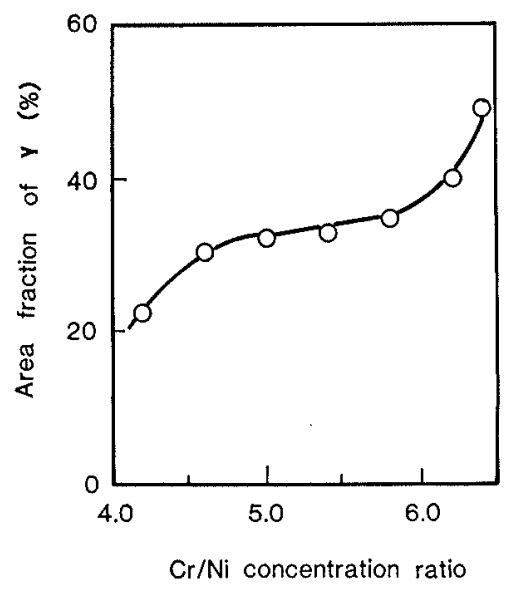

Fig. 7. Effect of the binarizing condition on area fraction of $\gamma$ phase in 329J1 stainless steel. and $\mathrm{Cr}$ in this work were made for 10 points selected randomly in austenitic stainless steels (16.1, 18.5 and $20.5 \mathrm{Cr}$ steels). The chemical composition analysis of $\mathrm{Ni}$ and $\mathrm{Cr}$ by the present system is highly reliable. It is, however, noted that the change in either the operating conditions of the EPMA or the binary threshold value may give rise to some little deviation in the composition analysis results.

Figs. 10 and 11 show the comparison between the present system and the GMA in color mapping of the concentrations of $\mathrm{Ni}$ and $\mathrm{Cr}$ in 329J1. Area fraction destributions by the present system and the CMA showed the same peak concentration ranges in $\mathrm{Gr}$ and $\mathrm{Ni}$. As a whole, both of the image analyzed data were found to be in fairly good agreement, though the values by the present system, especially in $\mathrm{Cr}$, were not in accord with those by the GMA. The difference between these two systems is possibly caused by characteristics of the equipment and operating conditions, further studies will be needed for

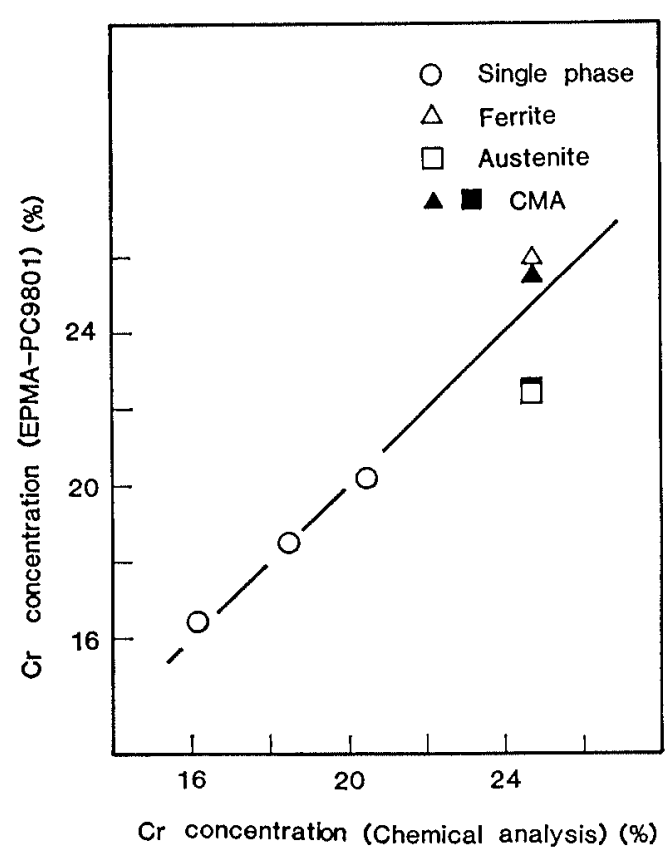

Fig. 9. Reliability of the present system for Cr concentration compared with chemical analysis of $\mathrm{Cr}$ concentration.

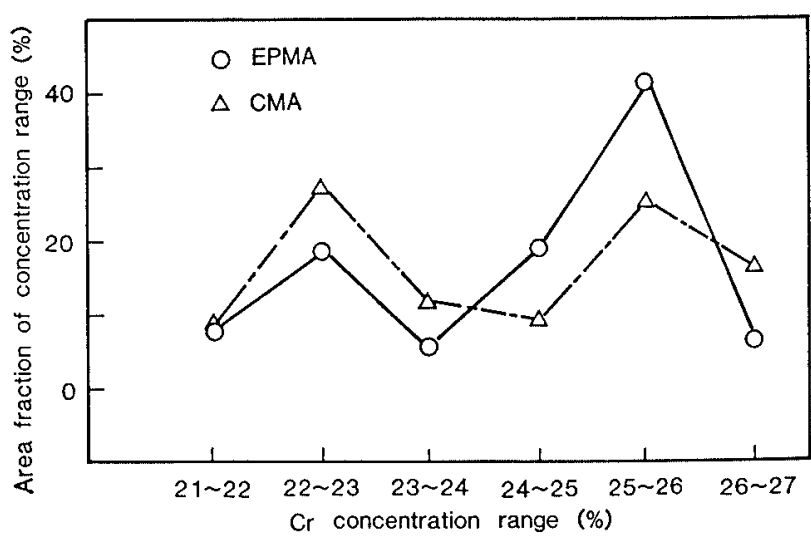

Fig. 10. Comparison of $\mathrm{Cr}$ concentrations by the present system and by CMA for $329 \mathrm{~J} 1$ stainless steel. 


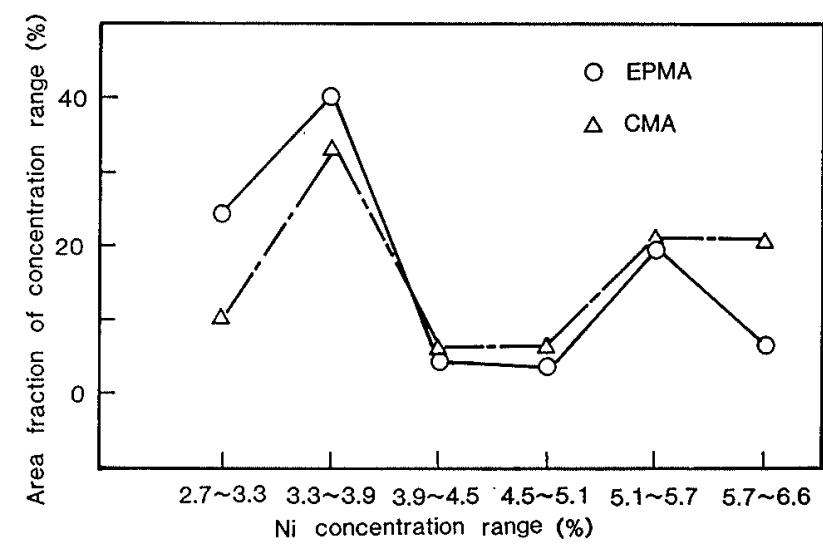

Fig. 11. Comparison of $\mathrm{Ni}$ concentrations by the present system and by CMA for $329 \mathrm{~J} 1$ stainless steel.

detailed evaluations for the present system.

In conclusion, the present system (EPMA-PG9801) can be easily introduced by utilizing personal computers and EPMA, and the application of this system for image analysis for small areas and the estimation of precipitation behavior possess high enough merit to compensate for the longer counting time for characteristic X-ray signals.

\section{Summary}

The utilization of the combination of a personal computer with EPMA was made in order to develop a conventional and low cost microanalysis equipment system which has nearly the same analyzing power as the CMA, and its application for metallic microstructure was investigated. The main results obtained are as follows;

(1) The analysis data was acceptable for $2 \mathrm{~s}$ counting of X-ray signals from the EPMA being operated under the following conditions: accelerating voltage $15 \mathrm{kV}$, emission current $6 \mathrm{nA}$, beam diameter $2 \mu \mathrm{m}$.

(2) Color mapping of the concentrations of $\mathrm{Ni}$ and $\mathrm{Gr}$ and the estimation of area fractions of these elements for a duplex stainless steel were evaluated, and it was confirmed that the results were in fairly good agreement with those of the CMA.

(3) Identification of $\alpha$ and $\gamma$ phases by $\mathrm{Cr} / \mathrm{Ni}$ partition ratio and color presentation were also possible using the present system.

\section{Acknowlegment}

The authors wish to express their thanks to Mr. H. Hamada in Nippon Steel Corporation for his experiments in collaboration with GMA.

\section{REFERENCES}

1) E. Kitamura, K. Kawashima, H. Soga, H. Ogawa, T. Saeki, M. Sato and J. Kaneko: Tetsu-to-Hagané, 70 (1984), 2294

2) I. Taguchi: Bull. Jpn. Inst. Met., 25 (1986), 160.

3) The Practical Quantitative Analysis in X-ray Microanalyzer (X-ray Microanalyzer Schooling Textbook), JEOL, Tokyo, (1980), (in Japanese). 